\title{
Fate of laparoscopic morcellation post-FDA warning: a literature review
}

\author{
Bose $\mathbf{D}^{1}$ \\ ${ }^{1}$ Dr. Deepak Bose, Senior Resident, KMCT Medical College, Calicut, Kerala, India.
}

Address for Correspondence: Dr. Deepak Bose, Email: docdeebose@ gmail.com

\begin{abstract}
In laparoscopy, tissue extraction might require morcellation for larger intra-abdominal specimens, especially in gynecological patients. specimen, the specimen needs to be reduced. The Food and Drug Administration (FDA) issued a press release in April 2014 that discouraged the use of devices used for morcellation - power morcellators. This article has the objective to review the literature related to complications by power morcellation of uterine fibroids in laparoscopy and offer recommendations to laparoscopic surgeons in gynaecology. Respecting women who have leiomyosarcoma, it can be concluded that the FDA directive was based on a mis-leading analysis due to inherent flaws in the trials analysed by it. Hence, the need of the hour are more accurate esti-mates regarding the prevalence of leiomyosarcoma among women having surgery for presumed leiomyomas. Modification of the FDA's current restriction regarding power morcellation would empower each woman to allow surgeons and hospitals to make the most appropriate, informed choices regarding utilization of tissue extraction in individual patients undergoing uterine surgery without undermining the freedom of the woman to choose the best-suited procedure.
\end{abstract}

Keywords: Laparoscopy, Morcellation, Food and Drug Administration, Leiomyoma, Leiomyosarcoma

\section{Introduction}

The benefits of laparoscopic (minimally invasive surgery, MIS) for gynecologic conditions requiring surgery have been clearly defined in the literature [1-3]. The focal points incorporate speedier recovery, less blood loss, enhanced personal satisfaction, and less morbidity [4]. One major difficulty for minimal access surgeons was those cases in which the uterus is too large to be evacuated through the laparoscopic entry point and would have to be extracted by means of a bigger laparotomy incision [5]. This issue was addressed by advancement of morcellation, which breaks the tissue into smaller pieces, either manually with a surgical blade or electromechanically with a power morcellator.

Morcellation, for which the US Food and Drug Administration (FDA) initially endorsed devices in 1995, was acknowledged up until 2014. As of now, reports were circulating depicting morcellation-induced dissemination of unrecognized uterine malignancies and

Manuscript received $24^{\text {th }}$ July 2016

Reviewed: $5^{\text {th }}$ August 2016

Author Corrected: $20^{\text {th }}$ August 2016

Accepted for Publication $31^{\text {st }}$ August 2016 thus result in diminished survival. These worries were conveyed to the media by an appalling instance of uterine leiomyosarcoma found in a young lady who experienced intra-abdominal morcellation of an unrecognized sarcoma and at reintervention was found to have a spread of the sarcoma in the abdominal cavity.

The FDA issued an announcement discouraging the utilization of power morcellation for hysterectomy and myomectomy [6].

Dreading prosecution, the organizations making power morcellators have stopped production of their items or have set notices on their item. Furthermore, hospitals have constrained the utilization of morcellation [7].

Chronology of morcellator controversy [8]

March 1993- Uterine morcellator first described in literature

May 1995- First uterine morcellation device cleared by FDA [9] 
July 1997- Reports of port-site metastasis in gynecologic oncology patients described [10]

November 2012- Study estimating higher than expected leiomyosarcoma rate [11]

October 2013- High-profile case sparks increasing media and public awareness of uterine morcellation practices [12]

December 2013- SGO position statement on morcellation released [13]

April 2014- SGO Lancet editorial in response to criticism published

-- FDA safety communication released

-- ACOG calls for review of morcellation

-- AAGL calls for review of morcellation

-- Some manufacturers voluntarily suspend sales of uterine morcellators $[12,14-17]$

July 2014- FDA convened obstetrical and gynecological medical device safety panel, immediately in effect guidance to manufacturers issued

-- AAGL statement to the FDA released $[14,16]$

November 2014- Updated FDA safety communication released

-- ACOG response released

-- AAGL response released [14-16]

May 2015- FBI launches inquiry into manufacturers' knowledge of risks [18]

Abbreviations: AAGL, American Association of Gynecologic Laparoscopists; ACOG, American Congress of Obstetricians and Gynecologists; FBI, Federal Bureau of Investigation; FDA, U.S. Food and Drug Administration; SGO, Society for Gynecologic Oncology

Uterine leiomyoma and leiomyosarcoma- Uterine leiomyoma or myoma (fibroid) is a type of smooth muscle tumour of the myometrium and (nemec) uterine leiomyosarcoma (ULMS) is a highly malignant, rapidly growing and a rare mesenchymal tumor which makes up to 1-2 \% of uterine malignancies [19]. The annual incidence of ULMS is 0.64 per 100,000 women per year [20].
Diagnosis of leiomyosarcoma (LMS) depends on the presence of cytologic atypia, a high mitotic index, and coagulative tumor cell necrosis to distinguish it from between benign leiomyoma and other smooth muscle tumours like atypical leiomyoma and endometrial stromal tumour. Although most LMSs arise in postmenopausal women, several cases have been reported in women of reproductive age [21].

On April 17, 2014, the FDA, after meta-analysing 18 studies, distributed an official statement on the site where the utilization of laparoscopic power morcellation was "debilitated" because of poten-tial upstaging of uterine sarcoma [21].

Complications of morcellation- Known complications are direct morcellation injuries wherever the activated morcellator injures intestines or blood vessels as reviewed by Milad et al. [22] Secondary to morcellation of fibroids, parasitic fibroids may develop with an incidence of $0.12-0.9 \%$ [23-25]. If a likely fibroid seems to be a sarcoma, the centripetal forces of the cylindrical morcellator knife might boost the development of 'seeding' of tumour cells on the serosa, probably upstaging the sarcoma with percentages between 15 and 64\% [11, 26-28] and affecting survival. Finally, the fragmented state of the morcellated specimen might impair correct histological analysis of the malignancy thus probably delaying treatment [29, 30].

Possible limitations of FDA regulation- The FDA's suggestions must be considered important, as patient wellbeing and avoidance of preventable damages are of foremost significance. In any case, the studies investigated by the FDA in detailing this suggestion were not stratified by risk variables for sarcoma and did not consider the subset of reproductive age ladies with assumed benign leiomyomata [11,31-34]. If morcellator use is suspended entirely, the choices for women with big uteri would include surrendering MIS and its advantages. In response, the American Congress of Obstetricians \& Gynecologists (ACOG) and the American Association of Gynecologic Laparoscopists (AAGL) have issued position papers supporting minimally invasive surgery for presumed benign disease in patients at low risk for malignancy [16,35].

\section{Aim}

In this review, we will be addressing important aspects regarding: (1) Impact of FDA restriction on clinical 
practice, (2) Incidence of unsuspected uterine leiomyosarcoma among ladies diagnosed with presumed benign uterine disease and the impact of morcellation on them, (3) Comparison of mor-bidity between minimally invasive surgery (MIS) and open abdominal procedures (4) Preoperative workup of patients with apparent benign uterine fibroids. (5) Minimally invasive techniques to avoid intracorporeal morcellation and bring out certain practical recommendations. In the Indian context, FDA guidelines are not usually followed, however, as patients become more aware of these international guidelines, our surgeons also need to keep themselves abreast of these developments and aware of further research into making minimally invasive surgeries more safe and effective.

\section{Materials and Methods}

A literature review was performed using Pubmed, Springer link and major general search engines like Google, and Yahoo. The following search terms were used: Laparoscopy, morcellation, leiomyoma, Food and Drug Administration warning, leiomyosarcoma. A total of 35 selected papers from after FDA warning in 2014 till present were cited. These articles were screened for further references and citations were analysed under the various headings; Impact of FDA warning on morcellation, incidence of sarcoma and effect of morcellation on malignancy, comparing laparoscopy and open procedures, preoperative workup of patients with fibroids and future prospects of morcellation.

\section{Results and Discussion}

Impact of FDA warning on clinical practiceProbably, an inability to assure benign pathology and a fear of aggravating the outcomes for patients with occult, aggressive malignancies, patients and surgeons are tending to move away from power morcellation as a surgical tool. A recent survey of laparoscopic surgeons found that $84 \%$ have changed their surgical approach to total abdominal hysterectomy after the FDA communication [36]. Although abdominal hysterectomy may decrease the specific risk of dissemination of occult malig-nancy, it may increase the surgical morbidity associated with open pro-cedures [37]. Consequently, patients and their surgeons may be trading the risk of one complication for another.

Studies have pointed out a decrease in minimally invasive gynecological surgeries over a range of 5.8 to
19\%. [38,39] The most common reasons cited for discontinuing the use of power morcellation were hospital mandate, the concern for legal consequences, and the April 2014 FDA warning. Nearly half of the respondents reported an increase in their rate of laparotomies, However, most $(80.3 \%)$ believed that the FDA warnings have not led to an improvement in patient outcomes and have led to harming patients $(55.1 \%)$.

Another recently published study [40] found that in the eight months following the FDA safety communication, utilization of laparoscopic hysterectomies decreased by $4.1 \%(\mathrm{p}=0.005)$ and both abdominal and vaginal hysterectomies increased $(1.7 \%, \mathrm{p}=0.112$ and $2.4 \%$, $\mathrm{p}=0.012$, respectively). Major surgical complications (not including blood transfusions) significantly increased from $2.2 \%$ to $2.8 \%(\mathrm{p}=0.015)$, and the rate of hospital readmission within 30 days also increased from $3.4 \%$ to $4.2 \%(\mathrm{p}=0.025)$.

Thus media portrayal and misperception of the FDA safety communication may have contributed to a heightened concern about any type of morcellation for any indication by patients and surgeons alike. The additional risks associated with changes in surgical practice, due to a decline in the use of morcellation, must be discussed with patients to provide comprehensive informed consent.

\section{Incidence of leiomyosarcomas and impact of morcellation on them}

Leiomyosarcoma incidence- The FDA analyzed available data and found the prevalence of unsuspected uterine sarcoma in women undergoing surgery for fibroids to be 1 in 352 [41]. This statistic has been challenged as an overestimate due to the inclusion of mixed patient populations and heterogeneous retrospective studies.

A recent study of women undergoing hysterectomy for benign indications found the prevalence of occult uterine sarcoma to be between 0.07 - to $0.49 \%$ $[11,34,42]$. The prevalence of leiomyosarcoma is 10 fold higher in women older than age 60 years when compared with women younger than age 50 years.

The FDA estimated that for every 458 women having surgery for presumed leiomyomas, one woman would be found to have an occult leiomyosarcoma. Parker et al [43] challenged this calculation. Nine studies, all but one of which were retrospective, were analyzed 
including a non peer- reviewed letter to the editor. Three leiomyosarcoma cases identified by the FDA would now be classified as benign atypical leiomyomas. If these discrepancies are corrected the actual prevalence should have been 1 in $1,550(0.064 \%)$.

Pritts et al [44] recently published a more rigorous meta- analysis of 133 studies and determined that the prevalence of leiomyosarcoma among women having surgery for presumed leiomyomas was 1 in 1,960 , or $0.051 \%$. Among the 26 randomized control trials analyzed, 1,582 women had surgery for leiomyomas and none were found to have leiomyosarcoma.

Bojahr et al [45] recently published a large populationbased prospective registry study and reported two occult leiomyosarcoma among 8,720 women having surgery for leiomyomas $(0.023 \%)$.

Morcellation concerns in undiagnosed sarcoma- One of the major concerns over morcellation of an occult cancer is delayed diagnosis because of misinterpretation of the initial pathologic specimen [31]. It is hypothesised that morcellation of an occult malignancy carries the possibility of the seeding of cancer throughout the peritoneal cavity $[11,27,29]$.

Certain case reports have also described up-staging of sarcoma secondary to peritoneal spread after morcellation [46,47]. However, these studies cannot rule out the possibility that disseminated peritoneal disease may be due to incorrect initial staging, natural disease progression, or incorrect follow-up diagnosis.

Leiomyosarcoma, removed intact without morcellation have a poor prognosis. Based on SEER data, the 5 year survival of Stage I LMS is only $63 \%$ compared with $14 \%$ for stage IV. Whether morcellation influences the prognosis of women with LMS is not known. Distant metastasis occurs early in the disease process, primarily hematogenous dissemination.

Two studies by Park et al. [48, 49] compared the survival of patients with uterine sarcoma with $(n=48)$ and without morcellation $(n=58)$ during surgery and demonstrated a significant difference of survival in favour of the non-morcellated group. When comparing the outcomes for women with morcellated and nonmorcellated LMS, Morice et. al., [28] found no difference in recurrence rates or overall and disease-free survival rates. In the only study to compare use of power- with scalpel-morcellation in women with LMS, Oduyebo et. al. [27] found no difference in outcomes.
Nemec et al. [50] concluded that women who underwent hysterectomy with morcellation had a better cumulative overall survival and recurrence free survival rates than women without morcellation. Of note, laparoscopic-aided morcellation allows the surgeon to inspect the pelvic and abdominal cavities and irrigate and remove tissue fragments under visual control. In contrast, the surgeon cannot visually inspect the peritoneal cavity during vaginal or minilaparotomy procedures.

Comparison of laparoscopic vs open abdominal procedures- Liu et al [51] in their review quoted a Cochrane systematic review of 27 randomized clinical trials that compared laparoscopic or vaginal hysterectomy to abdominal hysterectomy, and found that women who underwent a minimally invasive surgery had significantly less blood loss, fewer incisional infections or febrile episodes, shorter hospital stays, and speedier return to normal activities.

Wright et al. [52,53] used a cohort simulation model to compare the risks and benefits of three modalities of hysterectomy: 1) total abdominal, 2) laparoscopic, and 3) laparoscopic with power morcellation and found that overall, the safest surgical modality was laparoscopic hysterectomy without morcellation, especially for women older than age 60 years. However, for women younger than age 40 years, laparoscopic surgery with morcellation was associated with slightly fewer deaths per 10000 patients than abdominal hysterectomy.

Epstein et al. [54] recently reported on the financial impact of minimally invasive surgery on medical spending and employee absenteeism. On average, those women who underwent the minimally invasive procedure had 11.5 fewer days absent from work and $\$ 1500$ less in health plan spending per procedure.

As per ACOG, approximately 600,000 hysterectomies are done per year; in 2008, $10 \%$ of these were laparoscopic and as per Wright et al $>15 \%$ were performed with morcellation. Liu et al have estimated that if morcellation were to be totally avoided, 9000 women $(600,000 \times 0.10 \times 0.15)$ would have undergone laparotomy, yielding 99,000 more days absent from work per year and $\$ 13,500,000$ more in health plan spending per year. Other studies have demonstrated a significant decrease in postoperative narcotic use and incisional hernias formation and higher long-term quality-of-life scores with a minimally invasive approach compared with an open approach [55]. 
Preoperative workup to rule out malignancies- The differential diagnosis between uterine sarcomas and myomas still remains a challenging topic in gynecologic oncology. Despite recent advances in the accuracy of imaging techniques for gynecologic malignancies, consensus on preoperative findings to consider a leiomyoma as 'suspicious' is still lacking. In fact, data evaluating predictors of malignancy are mainly based on small retrospective case series.

No clear clinical features have distinguished benign uterine neoplasms reliably from malignant growths, even the traditionally taught feature of rapidly enlarging uterine size.

Black race has been associated with a 2-fold increased risk of carcinosarcoma and leiomyosarcoma. Increasing age, postmenopausal status and tamoxifen use $>5$ years are also nonspecific risk factors for uterine sarcomas.

Imaging- After clinical examination, transvaginal ultrasound (TVUS) should be the first choice imaging technique to investigate myome-trial lesions. The presence of a large, single, growing lesion with cystic degeneration and marked peripheral and central vascularity are all sonographic features supporting the presence of a suspect myometrial malignancy.

Power Doppler should be preferred over color Doppler, since the former allows to detect small ves-sels characterized by low flow velocities, regardless its direction [56]. Few studies suggested that the presence of a low tumor flow resistance index (RI) and the pulsatility index (PI) are described as lower in the presence of uterine sarcomas, although being inconclusive [56,57,58].

Elastography is a new interesting ultrasonographic tool allowing the evaluation of different tissues' densities; uterine sarcoma seems characterized by a typical mosaic pattern while fibroids are characterized by a more homogeneous pattern [59].

The need to morcellate can be predicted pre-operatively using 3D- Ultrasound (3 DUS) uterine volumes obtained by TVS with a fair degree of accuracy. Uteri less than $120 \mathrm{~mL}$ by 3D-US were very unlikely to require morcellation [60].

MR imaging is superior to CT scan to delineate the extent and the tissue characteristics of the lesion. MRI, with the heterogeneous hypointensity on T1-weighted images and intermediate-to-high signal intensity on T2- weighted images (due to necrosis and hemorrhagic foci), may help in differentiating be-tween a leiomyoma and a LMS. In a small series, contrast enhancement after administration of gadolinium (Gd)-DTPA was detected in all 10 LMS, but absent in 28 of 32 uterine degenerated leiomyoma patients [61].

In PET scan imaging of fibroids, usually fluorodeoxyglucose (FDG) is used, but also other molecules, such as deoxyfluorothymidine (FLT) or alphafluorobeta-estradiol (FES), FES may be more accurate in distinguishing LMS from fibroids than FDG, with an accuracy of respectively 93 and $81 \%$ [62].

Serum markers ( $\mathrm{LDH}$ and CA125)- In a prospective series of 227 patients, the total $\mathrm{LDH}$ and $\mathrm{LDH}$ isozyme type 3 were elevated in 10 patients with LMS as compared with degenerated leiomyomas. Elevated CA125 have been reported in patients with LMS, especially in advanced-staged LMS $[61,63]$.

Findings of a study by Matsuda et al. [64] suggest that the accuracy of the preoperative diagnosis of uterine smooth muscle tumours may be improved by using a combination of immunohistochemical findings like the expression of LMP2 (low-molecular-mass polypeptide 2) and Ki-67 and clinical findings (serum lactate dehydrogenase level and menopause).

The role of endometrial sampling without abnormal uterine bleeding in the detection of uterine sarcoma is not yet eluci-dated. Also the role of image-guided needle biopsies is not completely clear [63].

Combined tests- The combined use of dynamic MRI by Gd-DTPA and serum measurement of LDH (total and isozyme 3) seems to be useful in making a differentiated diagnosis of LMS from degenerated leiomyoma before treatment [61].

Nagai et al. [65] brought out a PREoperative Sarcoma Scoring system (PRESS) incorporating preoperative age, serum lactate dehydrogenase (LDH) levels and magnetic resonance imaging (MRI) findings. At its optimal cut-off value, the scoring system had an accuracy of $84.1 \%$, sensitivity of 0.8 , and specificity of 0.854 .

They then revised it into the revised PREoperative Sarcoma Scoring system rPRESS with an accuracy, positive predictive value, and negative predictive value of $93.7,92.3$, and $94.0 \%$, respectively [66]. 


\section{Minimally invasive techniques to avoid intracorporeal power morcellation}

Laparoscopi-Contained morcellation and retrieval of uteri or fibroids within specimen bags has been suggested to avoid spread. The method requires extension of a port site incision, single port incision or a small Pfannensteil incision. This has been extended to in-bag power morcellation [67-70]. Although the FDA safety communication explicitly suggests in- bag morcellation, if these spec-imen bags are accidentally cut, this may leave fragments of synthetic, nonab-sorbable material in the abdomen, which can result in theoretical additional morbidity, and would have an unknown effect on allowing microscopic tumor spill. As techniques such as morcellating the uterus in a containment bag become more common, we should obtain data on their safety and efficacy [71].

Anapolski et al. [72] conducted a study to obtain the first data concerning the safety of an endobag with three closable ports during morcellation and subsequent bag extraction under in vitro conditions, No loss of solid material or fluid was recorded during the morcellation test.

Serur et al. [67] in their 5 years of experience with an endoscopic bag for the extraction of large uteri without the use of a power morcellator, had no incidence of gross spillage, visually noted bag rupture, or other complications. Single-site in-bag morcellation performed with the new technique by Aoki et al. [73] requires neither bag penetration nor piercing with a trocar which may prove beneficial for preventing spillage and dissemination of tumour tissue.

Minilaparotomy- Although prior studies suggest any tumor injury with LMS is associated with adverse outcomes, the use of minilaparotomy and cold-knife exxtraperitonel morcellation has been suggested to reduce the risks of intra- peritoneal dissemination of benign or malignant tissues. Self- retaining retractors may provide pro-tection of the incision. Patients with thicker abdominal walls may be less optimal for this approach given their baseline wound complication risks with laparotomy.

Transvaginal- Transvaginal morcellation through a posterior colpotomy has been reported as an alternative approach for specimen retrieval in cases where an additional incision is required. This may be less preferable than minilaparotomy because of creating an incision in a contaminated field, the need for a second surgical approach, delaying intercourse, potentially promoting dyspareunia and iatrogenic peritoneal leio-myomatosis. For these reasons others have reported the use of a specimen bag for transvaginal morcellation. This indicates that no particular route of morcellation without some sort of containment is completely riskfree $[49,74]$.

\section{Clinical Recommendations}

- The risk of leiomyosarcoma is higher in older postmenopausal women, and greater caution should be exercised before recommending mor-cellation procedures for these women.

- Preoperatively, women aged 35 years or older with irregular uterine bleeding and presumed leiomyomas should have an endometrial biopsy and normal results of cervical cancer screening.

- Use transvaginal/transabdominal ultrasound for diagnosis. In case of poor visualisation, MRI with or without contrast (Gadolinium-DTPA), 2D Power Doppler ultrasound (PDUS) or 3D PDUS, LDH and iso-enzyme 3 assay are other options.

- Open procedures should be offered to all women who are considering minimally invasive proce-dures for leiomyomas

- Informed consent by the patient is of utmost importance and women wishing minimally invasive procedures with morcellation, including scalpel morcellation through the vagina or minilaparotomy, or laparoscopic power morcellation should understand the potential risk of decreased survival should leiomyosarcoma be present and it should be included in the consent procedure.

- For safe entry, enlarge the incision to the diameter of the morcellator to reduce the abdominal wall resistance.

- Make sure that the morcellator's blade remains locked inside the protecting tube during the morcellator insertion into the abdomen

- Keep the tip of the morcellator shaft in midline of the lower abdomen while introducing and during morcellation

- Morcellate only under continuous vision by the lateral peeling technique. Avoid penetrating the mass and losing the tip out of sight

- Morcellation should be away from intestines and blood vessels

- After morcellation, careful inspection for tissue fragments should be undertaken and copious irrigation of the pelvic and abdominal cavities 
should be performed to minimize the risk of retained tissue.

- Employ in-bag contained morcellation for intraabdominal specimens

\section{Conclusion}

Respecting women who have leiomyosarcoma, it can be concluded that the FDA directive was based on a mis-leading analysis. Specific guidelines for the use of power morcellation may be of benefit while awaiting advances in preoperative diagnosis of sarcomas.

Preoperative evaluation before hysterectomy includes cervical cytologic evidence and may include endometrial biopsy and pelvic imaging. If preoperative evaluation raises suspicion for malignancy, morcellation clearly should be avoided. Morcellation should be avoided in patients with age $>50$ years, menopause, history of tamoxifen use, pelvic radiation, or increased genetic risk for malignancy.

Surgeons should review surgical alternatives that include laparotomy, minilaparotomy, and colpotomy with possible manual morcellation vaginally or within an endoscopic bag. The impact of minimally invasive surgery on patient quality of life and the economic benefits of shorter recovery time and improved pain management should not be overlooked in gynecologic surgery. New surgical methods are being developed so that women with large uterine leiomyomata can still be offered laparoscopic surgery.

Funding: Nil, Conflict of interest: None initiated, Permission from IRB: Yes

\section{References}

1. Nieboer TE, Johnson N, Barlow D, Lethaby A, Tavender E, Curr E, Garry R, van Voorst S, Mol BW, Kluivers K. Surgical approach to hysterectomy for benign gynaecological disease. The Cochrane Library. 2006.

2. ACOG Committee Opinion No. 444: choosing the route of hysterectomy for benign disease. Obstet Gynecol. 2009 Nov;114(5):1156-8. doi: 10.1097/AOG. 0b013e3181c33c72.

3. Wiser A, Holcroft CA, Tulandi T, Abenhaim HA. Abdominal versus laparoscopic hysterectomies for benign diseases: evaluation of morbidity and mortality among 465,798 cases. Gynecological surgery. 2013 May 1;10(2):117-22.

4. Rosero EB, Kho KA, Joshi GP, Giesecke M, Schaffer JI.Comparison of robotic and laparoscopic hysterectomy for benign gynecologic disease. Obstet Gynecol. 2013 Oct;122(4):778-86. doi: 10.1097/AOG. 0b013e3182a4ee4d.

5. AAGL Advancing Minimally Invasive Gynecology Worldwide. AAGL practice report: Morcellation during uterine tissue extraction. J Minim Invasive Gynecol. 2014 Jul-Aug;21(4):517-30. doi: 10.1016/j.jmig.2014. 05.010. Epub 2014 May 24.

6. US Food and Drug Administration. Laparoscopic uterine power morcellation in hysterectomy and myomectomy: FDA safety communication. Online: http://www. fda. gov/medicaldevices/safety/ alertsandnotices /ucm393576. htm. 2014.

7. Arora KS, Spillman M, Milad M. Bits and pieces: the ethics of uterine morcellation. Obstet Gynecol. 2014 Dec;124(6):1199-201. doi: 10.1097/AOG. 0000000000000525.

8. Hall T, Lee SI, Boruta DM, GOODMAN A. Medical Device Safety and Surgical Dissemination of Unrecognized Uterine Malignancy: Morcellation in Minimally Invasive Gynecologic Surgery. Oncologist. 2015 Nov 1;20(11).

9. 10. 510(k) premarket notification. Device name: KSE Steiner electromechanic morcellator. Available at http://www.accessdata.fda.gov/scripts/cdrh/cfdocs/cfP MN/pmn.cfm?ID5K946147. Accessed June 22, 2016.

10. Walker JL, Piedmonte MR, Spirtos NM et al.Recurrence and survival after random assignment to laparoscopy versus laparotomy for comprehensive surgical staging of uterine cancer. Gynecologic Oncology Group LAP2 Study. J Clin Oncol 2012;30:695-700.

11. Seidman MA, Oduyebo $T$, Muto $M G$ et al. Peritoneal dissemination complicating morcellation of uterine mesenchymal neoplasms. PLoSOne 2012; 7:e50058. 
12. Cadjigal S. The morcellation controversy: A timeline. Available at http://www.medscape.com/ viewarticle/824081. Accessed June 22, 2016.

13. SGO position statement: Morcellation. Available at https://www.sgo.org/newsroom/positionstatements-

2/morcellation/. Accessed June 22, 2016.

14. Updated: Laparoscopic uterine power morcellation in hysterectomy and myomectomy: FDA safety communication. Available at http://www. fda.gov/ MedicalDevices/Safety/AlertsandNotices/ ucm424443.htm. Accessed June 22, 2016.

15. ACOG statement: FDA issues safety communication on laparoscopic uterine power morcellation in hysterectomy andmyomectomy. Available at http:// www.acog.org/AboutACOG/Announcements/FDAIssues-Safety-

Communication-on-Laparoscopic-UterinePower-

Morcellation. Accessed June 22, 2016.

16. AAGL statement to the FDA on power morcellation. Available at http://www.aagl.org/ aaglnews/aagl-statement-to-the-fda-on-

powermorcellation/. Accessed June 22, 2016.

17. Lowes R. J\&J suspends power morcellator sales over cancer risk. Available at http://www. medscape.com/viewarticle/824371. Accessed June 22, 2016.

18. Levitz J. FBI is investigating hysterectomy device found to spread uterine cancer. Available at http://www.wsj.com/articles/fbi-is-

investigatingsurgical-device-1432746641. Accessed June 22, 2016.

19. D'Angelo E, Prat J. Uterine sarcomas: a review. Gynecologic oncology. 2010 Jan 31;116(1):131-9.

20. Harlow BL, Weiss NS, Lofton S. The epidemiology of sarcomas of the uterus. Journal of the National Cancer Institute. 1986 Mar 1;76(3):399-402.

21. Giuntoli RL, Metzinger DS, DiMarco CS, Cha SS, Sloan JA, Keeney GL, Gostout BS. Retrospective review of 208 patients with leiomyosarcoma of the uterus: prognostic indicators, surgical management, and adjuvant therapy 2 . Gynecologic oncology. 2003 Jun 30;89(3):460-9.
22.Milad MP, Milad EA. Laparoscopic morcellatorrelated complications. J Minim Invasive Gynecol. 2014 May-Jun;21(3):486-91. doi: 10.1016/j.jmig.2013. 12.003. Epub 2013 Dec 10.

23. Donnez O, Jadoul P, Squifflet J, Donnez J. A series of 3190 laparoscopic hysterectomies for benign disease from 1990 to 2006: evaluation of complications compared with vaginal and abdominal procedures. BJOG. 2009 Mar;116(4):492-500. doi: 10.1111/j.14710528.2008.01966.x. Epub 2008 Nov 11.

24. Cucinella G, Granese R, Calagna G, Somigliana E, Perino A. Parasitic myomas after laparoscopic surgery: an emerging complication in the use of morcellator? Description of four cases. Parasitic myomas after laparoscopic surgery: an emerging complication in the use of morcellator? Description of four cases.

25. Leren V, Langebrekke A, Qvigstad E. Parasitic leiomyomas after laparoscopic surgery with morcellation. Acta Obstet Gynecol Scand. 2012 Oct;91(10):1233-6. doi: 10.1111/j.1600-0412. 2012.01453.x.

26. Oduyebo T, Rauh-Hain AJ, Meserve EE, Seidman MA, Hinchcliff E, George S, Quade B, Nucci MR, Del Carmen MG, Muto MG. The value of re-exploration in patients with inadvertently morcellated uterine sarcoma. Gynecol Oncol. 2014 Feb;132(2):360-5. doi: 10.1016/j.ygyno.2013.11.024. Epub 2013 Dec 1.

27. Morice P, Rodriguez A, Rey A, Pautier P, Atallah D, Genestie C, Pomel C, Lhommé C, Haie-Meder C, Duvillard P, Castaigne D. Prognostic value of initial surgical procedure for patients with uterine sarcoma: analysis of 123 patients. European journal of gynaecological oncology. 2002 Dec;24(3-4):237-40.

28. Einstein MH, Barakat RR, Chi DS, Sonoda Y, Alektiar KM, Hensley ML, Abu-Rustum NR. Management of uterine malignancy found incidentally after supracervical hysterectomy or uterine morcellation for presumed benign disease. Int $\mathrm{J}$ Gynecol Cancer. 2008 Sep-Oct;18(5):1065-70. Epub 2007 Nov 6.

29. Hagemann IS, Hagemann AR, LiVolsi VA, Montone KT, Chu CS. Risk of occult malignancy in morcellated hysterectomy: a case series. Int J Gynecol Pathol. 2011 Sep;30(5):476-83. doi: 10.1097/ PGP.0b013e3182107ecf. 
30. Rivard C, Salhadar A, Kenton K. New challenges in detecting, grading, and staging endometrial cancer after uterine morcellation. J Minim Invasive Gynecol. 2012 May-Jun;19(3):313-6. doi: 10.1016/j.jmig.2011.12.019. Epub 2012 Mar 13.

31. Sinha R, Sundaram M, Lakhotia S, Kadam P, Rao G, Mahajan C. Parasitic myoma after morcellation. Journal of gynecological endoscopy and surgery. 2009 Jul 1;1(2):113.

32. Kamikabeya TS, Etchebehere RM, Nomelini RS, Murta EF. Gynecological malignant neoplasias diagnosed after hysterectomy performed for leiomyoma in a university hospital. Eur $\mathrm{J}$ Gynaecol Oncol. 2010;31(6):651-3.

33. Leung F, Terzibachian JJ. Re: "The impact of tumor morcellation during surgery on the prognosis of patients with apparently early uterine leiomyosarcoma". Gynecol Oncol. 2012 Jan;124(1):172-3; author reply 173. doi: 10.1016/j.ygyno.2011.08.035. Epub 2011 Sep 28.

34. Rowland M, Lesnock J, Edwards R, Richard S, Zorn K, Sukumvanich P, Krivak T. Occult uterine cancer in patients undergoing laparoscopic hysterectomy with morcellation. Gynecologic oncology. 2012 Oct $31 ; 127(1):$ S29.

35. ACOG Statement on Power Morcellation. Available at http://www.acog.org/About-ACOG/News-Room/ Statements/2014/ACOG-Statement-on-Power-

Morcellation. Accessed on June 22,2016

36. Desai VB, Guo XM, Xu X. Alterations in surgical technique after FDA statement on power morcellation. Am J Obstet Gynecol. 2015 May;212(5):685-7. doi: 10.1016/j.ajog.2015.02.027. Epub 2015 Feb 28.

37. Siedhoff MT, Wheeler SB, Rutstein SE, Geller EJ, Doll KM, Wu JM, Clarke-Pearson DL. Laparoscopic hysterectomy with morcellation vs abdominal hysterectomy for presumed fibroid tumors in premenopausal women: a decision analysis. Am J Obstet Gynecol. 2015 May;212(5):591.e1-8. doi: 10.1016/j.ajog.2015.03.006. Epub 2015 Mar 24.

38. Barron KI, Richard T, Robinson PS, Lamvu G. Association of the U.S. Food and Drug Administration Morcellation Warning With Rates of Minimally
Invasive Hysterectomy and Myomectomy. Obstet Gynecol. 2015 Dec;126(6):1174-80. doi: 10.1097/ AOG.0000000000001111.

39. Lum DA, Sokol ER, Berek JS, Schulkin J, Chen L, McElwain CA, Wright JD. Impact of the 2014 Food and Drug Administration Warnings Against Power Morcellation. J Minim Invasive Gynecol. 2016 MayJun;23(4):548-56. doi: 10.1016/j.jmig.2016.01.019. Epub 2016 Jan 28.

40. Harris JA, Swenson CW, Uppal S, Kamdar N, Mahnert N, As-Sanie S, Morgan DM. Practice patterns and postoperative complications before and after US Food and Drug Administration safety communication on power morcellation. Am J Obstet Gynecol. 2016 Jan;214(1):98.e1-98.e13. doi: 10.1016/j.ajog. 2015.08.047. Epub 2015 Aug 24.

41. Quantitative assessment of the prevalence of unsuspected uterine sarcoma in women undergoing treatment of uterine fibroids: Summary and key findings, April 2014. Available at http://www.fda.gov/ downloads/MedicalDevices/Safety/AlertsandNotices/ UCM393589.pdf. Accessed June 22, 2016

42. Mahnert N, Morgan D, Campbell D, Johnston C, As-Sanie S. Unexpected gynecologic malignancy diagnosed after hysterectomy performed for benign indications. Obstetrics \& Gynecology. 2015 Feb 1;125(2):397-405.

43. Parker WH, Kaunitz AM, Pritts EA, Olive DL, Chalas E, Clarke-Pearson DL, Berek JS; Leiomyoma Morcellation Review Group. U.S. Food and Drug Administration's Guidance Regarding Morcellation of Leiomyomas: Well-Intentioned, But Is It Harmful for Women? Obstet Gynecol. 2016 Jan;127(1):18-22. doi: 10.1097/AOG.0000000000001157.

44. Pritts EA, Vanness DJ, Berek JS, Parker W, Feinberg R, Feinberg J, Olive DL. The prevalence of occult leiomyosarcoma at surgery for presumed uterine fibroids: a meta-analysis. Gynecol Surg. 2015;12(3):165-177. Epub 2015 May 19.

45. Bojahr B, De Wilde RL, Tchartchian G. Malignancy rate of 10,731 uteri morcellated during laparoscopic supracervical hysterectomy (LASH). Archives of gynecology and obstetrics. 2015 Sep 1;292(3):665-72. 
46. Anupama R, Ahmad SZ, Kuriakose S, Vijaykumar DK, Pavithran K, Seethalekshmy NV. Disseminated peritoneal leiomyosarcomas after laparoscopic "myomectomy" and morcellation. J Minim Invasive Gynecol. 2011 May-Jun;18(3):386-9. doi: 10.1016/j. jmig.2011.01.014.

47. Della Badia C, Karini H. Endometrial stromal sarcoma diagnosed after uterine morcellation in laparoscopic supracervical hysterectomy. Journal of minimally invasive gynecology. 2010 Dec 31;17(6):791-3.

48. Park JY, Kim DY, Kim JH, Kim YM, Kim YT, Nam JH. The impact of tumor morcellation during surgery on the outcomes of patients with apparently early low-grade endometrial stromal sarcoma of the uterus. Ann Surg Oncol. 2011 Nov;18(12):3453-61. doi: 10.1245/s10434-011-1751-y. Epub 2011 May 4.

49. Park JY, Park SK, Kim DY, Kim JH, Kim YM, Kim YT, Nam JH. The impact of tumor morcellation during surgery on the prognosis of patients with apparently early uterine leiomyosarcoma. Gynecol Oncol. 2011 Aug;122(2):255-9. doi: 10.1016/j.ygyno.2011.04.021. Epub 2011 May 12.

50. Gao Z, Li L, Meng Y. A Retrospective Analysis of the Impact of Myomectomy on Survival in Uterine Sarcoma. PLoS One. 2016 Feb 1;11(2):e0148050. doi: 10.1371/journal.pone.0148050. eCollection 2016.

51.Liu FW, Galvan-Turner VB, Pfaendler KS, Longoria TC, Bristow RE. A critical assessment of morcellation and its impact on gynecologic surgery and the limitations of the existing literature. Am J Obstet Gynecol. 2015 Jun;212(6):717-24. doi: 10.1016/j.ajog.2015.01.012. Epub 2015 Jan 9.

52. Wright JD, Cui RR, Wang A, Chen L, Tergas AI, Burke WM, Ananth CV, Hou JY, Neugut AI, Temkin SM, Wang YC, Hershman DL. Economic and Survival Implications of Use of Electric Power Morcellation for Hysterectomy for Presumed Benign Gynecologic Disease. J Natl Cancer Inst. 2015 Oct 8;107(11). pii: djv251. doi: 10.1093/jnci/djv251. Print 2015 Nov.

53. Mutch DG. Premature Judgment of Uterine Morcellation: Look at the Data Before You Leap. Journal of the National Cancer Institute. 2015 Nov 1;107(11):djv283.
54. Epstein AJ, Groeneveld PW, Harhay MO, Yang F, Polsky D. Impact of minimally invasive surgery on medical spending and employee absenteeism. JAMA Surg. 2013 Jul;148(7):641-7. doi: 10.1001/ jamasurg.2013.131.

55. Nieboer TE, Hendriks JC, Bongers MY, Vierhout ME, Kluivers KB. Quality of life after laparoscopic and abdominal hysterectomy: a randomized controlled trial. Obstet Gynecol. 2012 Jan;119(1):85-91. doi: 10.1097/AOG.0b013e31823d3b00.

56. Nagai T, Takai Y, Akahori T, Ishida H, Hanaoka T, Uotani T, Sato S, Matsunaga S, Baba K, Seki H. Highly improved accuracy of the revised PREoperative sarcoma score (rPRESS) in the decision of performing surgery for patients presenting with a uterine mass. Springerplus. 2015 Sep 17;4:520. doi: 10.1186/s40064015-1318-7. eCollection 2015.

57. Van den Bosch T, Dueholm M, Leone FP, Valentin L, Rasmussen CK, Votino A, Van Schoubroeck D, Landolfo C, Installé AJ, Guerriero S, Exacoustos C. Terms, definitions and measurements to describe sonographic features of myometrium and uterine masses: a consensus opinion from the Morphological Uterus Sonographic Assessment (MUSA) group. Ultrasound in Obstetrics \& Gynecology. 2015 Sep 1;46(3):284-98.

58. Wu TI, Yen TC, Lai CH. Clinical presentation and diagnosis of uterine sarcoma, including imaging. Best Practice \& Research Clinical Obstetrics \& Gynaecology. 2011 Dec 31;25(6):681-9.

59. Nitta E, Kanenishi K, Itabashi N, Tanaka H, Hata T. Real-time tissue elastography of uterine sarcoma. Archives of gynecology and obstetrics. 2014 Feb $1 ; 289(2): 463-5$.

60.Gerges B, Mongelli M, Casikar I, Bignardi T, Condous G. 3D transvaginal sonography as preoperative predictor of the need to morcellate in women undergoing laparoscopic hysterectomy. Ultrasound Obstet Gynecol. 2016 Jun 9. doi: 10.1002/uog.15991. [Epub ahead of print]

61. Goto A, Takeuchi S, Sugimura K, Maruo T. Usefulness of Gd-DTPA contrast-enhanced dynamic MRI and serum determination of LDH and its isozymes in the differential diagnosis of leiomyosarcoma from 
degenerated leiomyoma of the uterus. International Journal of Gynecological Cancer. 2002 Jul 1;12(4): 354-61.

62. Yoshida Y, Kiyono Y, Tsujikawa T, Kurokawa T, Okazawa H, Kotsuji F. Additional value of $16 \alpha-[18 \mathrm{~F}]$ fluoro-17 $\beta$-oestradiol PET for differential diagnosis between uterine sarcoma and leiomyoma in patients with positive or equivocal findings on [18F] fluorodeoxyglucose PET. European journal of nuclear medicine and molecular imaging. 2011 Oct $1 ; 38(10): 1824-31.1$

63. Brölmann H, Tanos V, Grimbizis G, Ind T, Philips $\mathrm{K}$, van den Bosch T, Sawalhe S, van den Haak L, Jansen FW, Pijnenborg J, Taran FA. Options on fibroid morcellation: a literature review. Gynecological surgery. 2015 Feb 1;12(1):3-15.

64. Matsuda M, Ichimura T, Kasai M, Murakami M, Kawamura N, Hayashi T, Sumi T. Preoperative diagnosis of usual leiomyoma, atypical leiomyoma, and leiomyosarcoma. Sarcoma. 2014 Oct 21;2014.

65. Nagai T, Takai Y, Akahori T, Ishida H, Hanaoka T, Uotani T, Sato S, Matsunaga S, Baba K, Seki H. Highly improved accuracy of the revised PREoperative sarcoma score (rPRESS) in the decision of performing surgery for patients presenting with a uterine mass. Springerplus. 2015 Sep 17;4:520. doi: 10.1186/s40064015-1318-7. eCollection 2015.

66. Nagai T, Takai Y, Akahori T, Ishida H, Hanaoka T, Uotani T, Sato S, Matsunaga S, Baba K, Seki H. Highly improved accuracy of the revised PREoperative sarcoma score (rPRESS) in the decision of performing surgery for patients presenting with a uterine mass. Springerplus. 2015 Sep 17;4:520. doi: 10.1186/s40064015-1318-7. eCollection 2015

67. Serur E, Lakhi N. Laparoscopic hysterectomy with manual morcellation of the uterus: an original technique that permits the safe and quick removal of a large uterus. American journal of obstetrics and gynecology. 2011 Jun 30;204(6):566-e1.

68. Senapati S, Tu FF, Magrina JF. Power morcellators: a review of current practice and assessment of risk. American journal of obstetrics and gynecology. 2015 Jan 31;212(1):18-23.

69. Kim YW, Park BJ, Ro DY, Kim TE. Single-port laparoscopic myomectomy using a new single-port transumbilical morcellation system: initial clinical study. Journal of minimally invasive gynecology. 2010 Oct 31;17(5):587-92.

70. Einarsson JI, Cohen SL, Fuchs N, Wang KC. In-bag morcellation. Journal of minimally invasive gynecology. 2014 Oct 31;21(5):951-3.

71. Cohen SL, Einarsson JI, Wang KC, Brown D, Boruta D, Scheib SA, Fader AN, Shibley T. Contained power morcellation within an insufflated isolation bag. Obstetrics \& Gynecology. 2014 Sep 1;124(3):491-7.

72. Anapolski M, Panayotopoulos D, Alkatout I, Soltesz S, Schiermeier S, Noé G. Preclinical safety testing for morcellation and extraction for an endobag with sealable ports: in vitro pilot study. Surgical endoscopy. 2016 May 18:1-7.

73. Aoki Y, Matsuura M, Matsuno T, Yamamoto $T$. Single-site in-bag morcellation achieved via direct puncture of the pneumoperitoneum cap, a cordless electric morcellator, and a 5-mm flexible scope. European Journal of Obstetrics \& Gynecology and Reproductive Biology. 2016 Jun 30;201:126-30.

74. Serur E, Lakhi N. Tips and tricks for successful manual morcellation: a response to "vaginal morcellation: a new strategy for large gynecological malignant tumor extraction". Gynecologic oncology. 2013 Jan 1;128(1):150.

\section{How to cite this article?}

Bose D.Fate of laparoscopic morcellation post-FDA warning: a literature review. Int J Med Res Rev 2016;4(10):18711881.doi:10.17511/ijmrr. 2016.i10.26. 